\title{
Factors Attributable to the LeVel of Exhaled Nitric Oxide in ASTHMATIC CHILDREN
}

\author{
P. Banovcin ${ }^{1,2}$, M. Jesenak1,2,3, Z. Michnova ${ }^{1}$, E. Babusikova2, 4, S. Nosal1,2, J. Mikler¹, 2, J. Fabry ${ }^{5}$, \\ M. Barreto ${ }^{3}$
}

\begin{abstract}
${ }^{1}$ Department of Pediatrics and ${ }^{2}$ Center of Experimental and Clinical Respirology, Comenius University in Bratislava, Jessenius School of Medicine, Martin, Slovakia; ${ }^{3}$ Department of Pediatrics, Second School of Medicine, University 'La Sapienza', Rome, Italy; ${ }^{4}$ Department of Medical Biochemistry, Jessenius School of Medicine, Comenius University, Martin, Slovakia; ${ }^{5}$ Srobar's Institute for Respiratory Diseases and Tuberculosis in Children, Dolny Smokovec, High Tatras, Slovakia
\end{abstract}

\begin{abstract}
Background: Asthma is a heterogeneous disease with variable symptoms especially in children. Exhaled nitric oxide (FeNO) has proved to be a marker of inflammation in the airways and has become a substantial part of clinical management of asthmatic children due to its potential to predict possible exacerbation and adjust the dose of inhalant corticosteroids.

Objectives: We analyzed potential factors that contribute to the variability of nitric oxide in various clinical and laboratory conditions.

Material and methods: Study population consisted of 222 asthmatic children and 27 healthy control subjects. All children underwent a panel of tests: fractioned exhaled nitric oxide, exhaled carbon monoxide, asthma control test scoring, blood sampling, skin prick tests, and basic spirometry.

Results: FeNO and other investigated parameters widely changed according to clinical or laboratory characteristics of the tested children. Asthmatics showed increased levels of FeNO, exhaled carbon monoxide, total serum IgE, and higher eosinophilia. Boys had higher FeNO levels than girls. We found a significant positive correlation between FeNO levels and the percentage of blood eosinophils, \%predicted of forced vital capacity, total serum IgE levels, and increasing age.

Conclusions: Various phenotypes of children's asthma are characterized by specific pattern of the results of clinical and laboratory tests. FeNO correlates with total serum IgE, blood eosinophilia, age, and some spirometric parameters with different strength. Therefore, the coexistence of atopy, concomitant allergic rhinitis/rhinoconjunctivitis, and some other parameters should be considered in critical evaluation of $\mathrm{FeNO}$ in the management of asthmatic children.
\end{abstract}

Key words: bronchial asthma, exhaled carbon monoxide, exhaled nitric oxide, children

\section{INTRODUCTION}

Asthma is a heterogenous disease with variable signs and symptoms expressed inter- but also intraindividu- ally, especially in children. There are not really specific diagnostic tools or surrogate markers for detecting asthma in infancy. Therefore, diagnosis is usually possible only through long-term follow-up [1]. Another important task is the optimal monitoring of children with confirmed asthma diagnosis and predicting the exacerbations. Beside detailed and repeated analysis of history and careful physical examination, several tests can be applied for this purpose: lung function testing, exercise testing and inflammometry (exhaled nitric oxide, exhaled carbon monoxide, 8-isoprostanes, alkanes, exhaled breath condensate analysis) [1,2]. Exhaled nitric oxide (FeNO) has proved to be a marker of inflammation in the airways and after initial use for investigation purposes, recently, the measurement of FeNO has become a substantial part of clinical management of asthmatic children due to its potential to predict possible exacerbation and adjust the dose of inhalant corticosteroids. It has been demonstrated that $\mathrm{FeNO}$ is elevated in various phenotypes of bronchial asthma (especially in atopic asthma) and that the metabolites of FeNO regulate airway inflammation and airway diameter. It is known that FeNO is not highly specific for pulmonary inflammation, since its can also be observed in non-asthmatic patients suffering from allergic rhinitis [3] or atopic eczema [4, 5]. Many studies searched and analyzed potential factors that regulate production of $\mathrm{NO}$ in various pathological and physiological conditions and which are associated with elevated levels in exhaled breath. The evaluation of the degree of asthma control is sometimes difficult, especially in children. For this purpose, FeNO has been introduced into daily practice as an objective parameter assessing, to some extent, the asthma control. FeNO should be evaluated critically, as many factors besides the inflammation presented in the airways modify its variability and levels [6].

In the present study, we aimed to compare differences among various subgroups of asthmatic children in the results of standardized tests and examinations commonly used in management of bronchial asthma. Another important task was to analyze all potential factors that are attributable to changes in fractioned exhaled nitric oxide. 


\section{Material And Methods}

The study was approved by the Ethical Committee of Jessenius School of Medicine in Martin, Slovakia. Written informed consent was obtained from the parents of all tested children.

We examined a population of 249 schoolchildren (aged $12 \pm 4$ years, 55\% boys). The study was performed at the Department of Pediatrics in University Hospital in Martin, Slovakia. Bronchial asthma was defined as recurrent airways obstruction manifested by wheeze and dyspnea relieved spontaneously or by bronchodilator therapy, as defined in GINA. Altogether, we enrolled 222 asthmatic children (89\%) and 27 healthy control subjects of comparable age without any allergic disease or subclinical atopy $(11 \%)$. None of the studied subjects was smoking. The children or their parents filled standardized Asthma control test ${ }^{\circledR}$ and questionnaire aimed at personal and family history of allergic and respiratory diseases, frequency of upper or lower respiratory infections, presence of pets at home, actual clinical complaints and signs of respiratory disease, and provided therapy. The children underwent blood sampling for blood cell count and basic biochemical analysis (C-reactive protein, total $\mathrm{IgE}$ in serum) and also the measurement of $\mathrm{FeNO}$ and exhaled carbon monoxide (eCO). FeNO was measured online according to the recommendations of the ERS/ATS standards [7], using a portable nitric oxide analyzer (NIOX-MINO ${ }^{\circledR}$, Aerocrine, Sweden). eCO was measured with a Micro 4 Smokerlyzer ${ }^{\circledR}$ (Bedfont, England). We also performed basic spirometry (KoKo DigiDoser-Spirometer; nSpire Health, Louisville, CO) according to the ATS/ERS recommendations [8]. The FeNO and eCO values were estimated prior to the spirometric examination.

Due to the possibility of discontinuance of antihistamine treatment, we performed a skin prick tests (SPT), with a panel of common inhalant allergens (Dermatophagoides pteronyssinus; cat dander; dog dander; feather mix; mixed 4 cereals; mixed 5 grasses: Avena sativa, Hordeum vulgare, Secale cereale, Triticum sativum; mixed moulds: Cladosporium herbatum, Aspergilus mix, Alternaria alternata; Artemisia vulgaris, Artemisia folia, Betula alba) (ALK-ABELLO, Hørsholm, Denmark), and we measured the levels of specific serum $\operatorname{IgE}(\mathrm{s} g \mathrm{E}$ ) against the same allergens (ELISA). The STP with allergens was defined as positive if the wheal was $\geq 3 \mathrm{~mm}$ in its longest dimension. All the tests were performed by the same welltrained operator. The children with at least one positive SPT or sIgE were considered as atopic.

Data are expressed as means $\pm \mathrm{SE}$ unless otherwise indicated and were analyzed with the SPSS version 9.0 (SPSS Inc. Chicago, IL). Student's two-tailed t-test or Mann-Whitney U non-parametric test was used for statistical comparison. Spearman's correlation $(\mathrm{rS})$ was used for correlation studies. $\mathrm{P} \leq 0.05$ was considered to indicate statistical significance.

\section{RESULTS}

Regarding the clinical control of asthma, 28 children $(12 \%)$ underwent testing during acute exacerbation (shortness of breath, wheezing, chest tightness, and/or coughing), while the rest of the children $(87 \%$, $194 / 222)$ had clinically controlled asthma. Thirty percent of the asthmatics $(67 / 222)$ did not suffer from any other allergic disease, but $70 \%$ of the children $(155 / 222)$ also had symptoms of concomitant allergic rhinitis/rhinoconjunctivitis (ARC). According to the results of SPT and specific $\mathrm{IgE}, 69 \%$ of the children suffered from atopic asthma (126/183) and the rest was non-atopic $(57 / 183,31 \%)$. Non-compliance with recommended therapy was noted in $23 \%$ of the children.

FeNO and other investigated parameters substantially differed according to clinical or laboratory characteristics of the tested children (Table 1). Comparing asthmatic children with healthy subjects, we found increased FeNO $(25.2 \pm 1.8$ vs. $12.4 \pm 1.2 \mathrm{ppb}, \mathrm{P}=0.043)$ and $\mathrm{eCO}(1.0 \pm 0.1$ vs. $0.4 \pm 0.2 \mathrm{ppm}, \mathrm{P}=0.013)$. Asthmatics had a higher level of eosinophilia in peripheral blood (absolute: $0.41 \pm 0.12 \times 103$ vs. $0.14 \pm 0.02 \times$ $10^{3} / \mathrm{ml}, \mathrm{P}=0.001$; percentage: $4.0 \pm 0.3$ vs. $2.2 \pm 0.3 \%$, $\mathrm{P}=0.005)$ and of total serum $\operatorname{IgE}(234.4 \pm 26.3$ vs. $31.8 \pm 4.8 \mathrm{U} / \mathrm{ml}, \mathrm{P}=0.005)$ compared with controls. All spirometric parameters were lower in asthmatics,

Table 1. Comparison of selected parameters in subgroups of asthmatic children and healthy controls.

\begin{tabular}{|c|c|c|c|c|c|c|}
\hline & $\begin{array}{c}\text { FeNO } \\
(\mathrm{ppb})\end{array}$ & $\begin{array}{l}\mathrm{eCO} \\
(\mathrm{ppm})\end{array}$ & $\begin{array}{l}\text { ACT } \\
\text { (score) }\end{array}$ & $\begin{array}{l}\text { Serum IgE } \\
(\mathrm{U} / \mathrm{ml})\end{array}$ & $\begin{array}{c}\text { Eosinophils } \\
\left(10^{9} / 1\right)\end{array}$ & $\begin{array}{c}\text { Eosinophils } \\
(\%)\end{array}$ \\
\hline $\mathrm{BA}$ & $25.2 \pm 1.8$ & $1.0 \pm 0.1$ & $22.7 \pm 0.2$ & $234.4 \pm 46.3$ & $0.41 \pm 0.12$ & $4.0 \pm 0.3$ \\
\hline BA acute & $63.0 \pm 8.6^{* * *}+1+$ & $1.2 \pm 0.2 \dagger$ & $20.6 \pm 0.8^{* *}$ & $503.2 \pm 136.7 * * *+1 t$ & $0.46 \pm 0.15 \mathrm{ttt}$ & $5.2 \pm 1.4 t \dagger$ \\
\hline BA stable & $20.1 \pm 1.3$ & $1.0 \pm 0.1 \dagger$ & $22.9 \pm 0.2$ & $200.5 \pm 23.2 \dagger$ & $0.40 \pm 0.12 \mathrm{tt}$ & $3.8 \pm 0.2 \mathrm{tt}$ \\
\hline BA atopic & $31.2 \pm 2.8 * * *+t$ & $1.0 \pm 0.1 \dagger$ & $22.6 \pm 0.3$ & $285.9 \pm 41.1 * * *++t$ & $0.52 \pm 0.18^{* *+t t}$ & $4.8 \pm 0.4^{* *+t \dagger}$ \\
\hline BA non-atopic & $14.9 \pm 1.6$ & $1.1 \pm 0.1 \dagger$ & $23.4 \pm 0.3$ & $115.8 \pm 26.4$ & $0.28 \pm 0.10 \mathrm{tt}$ & $2.9 \pm 0.3$ \\
\hline $\mathrm{BA}$ isolated & $20.5 \pm 2.7$ & $0.9 \pm 0.1$ & $22.8 \pm 0.4$ & $204.2 \pm 0.4 \dagger$ & $0.28 \pm 0.05 \mathrm{tt}$ & $3.8 \pm 0.5 \mathrm{tt}$ \\
\hline $\mathrm{BA}+\mathrm{ARC}$ & $27.3 \pm 2.3 * *+t$ & $1.1 \pm 0 .{ }^{1+\dagger}$ & $22.6 \pm 0.3$ & $247.3 \pm 33.5 \mathrm{tt}$ & $0.47 \pm 0.16 \mathrm{ttt}$ & $4.1 \pm 0.3+t$ \\
\hline Controls & $12.4 \pm 1.2$ & $0.4 \pm 0.2$ & --- & $31.8 \pm 4.8$ & $0.14 \pm 0.02$ & $2.2 \pm 0.3$ \\
\hline
\end{tabular}

FeNO - fractioned exhaled nitric oxide, eCO - exhaled carbon monoxide, ACT - asthma control test, BA - bronchial asthma, ARC - allergic rhinoconjunctivitis; Comparison between two asthmatic subgroups: ${ }^{*} \mathrm{P}<0.05, * * \mathrm{P}<0.01, * * * \mathrm{P}<0.001$; Comparison between asthmatic subgroup and healthy controls: $\mathrm{t} \mathrm{P}<0.05, \mathrm{t} \mathrm{P}<0.01, \mathrm{tt} \mathrm{P}<0.001$. 

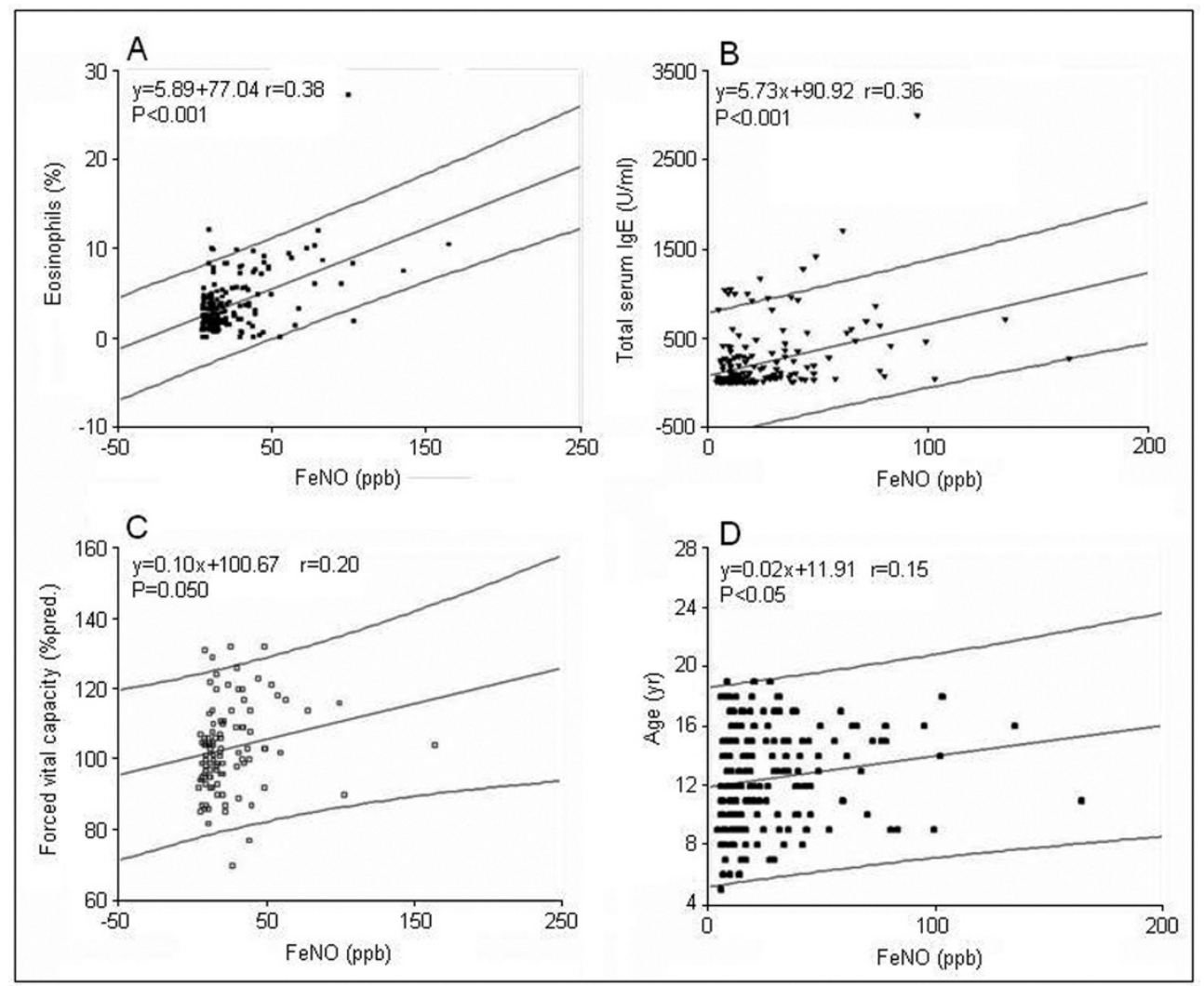

Fig. 1. Panel A - Correlation between fractioned exhaled nitric oxide and blood eosinophils; Panel B

Correlation between fractioned exhaled nitric oxide and total serum IgE; Panel C - Correlation between fractioned exhaled nitric oxide and forced vital capacity; Panel D Correlation between fractioned exhaled nitric oxide and age.

but the differences did not reach statistical significance. Analyzing the results among the groups of children divided according to the clinical control, the highest levels of $\mathrm{FeNO}$ were in asthmatic children during acute exacerbation compared with both stable asthmatics (63.0 \pm 8.6 vs. $20.1 \pm 1.3 \mathrm{ppb}, \mathrm{P}<0.001)$ and healthy controls $(63.0 \pm 8.6$ vs. $12.9 \pm 1.4 \mathrm{ppb}$, $\mathrm{P}<0.001)$. Stable asthmatics did not differ with controls regarding the FeNO. eCO, total serum $\operatorname{IgE}$, and eosinophils in peripheral blood were in general higher in asthmatics compared with healthy children, but we did not find the difference in eCO between asthmatic in acute and stable phases of the disease. Acute asthmatics had a lower total score in asthma control test than stable asthmatic children $(20.6 \pm 0.8$ vs. $22.9 \pm$ $0.2, \mathrm{P}=0.002)$. Neutrophils in blood were increased in acute (absolute: $5.69 \pm 0.63 \times 10^{9}$ vs. $2.06 \pm 0.32 \mathrm{x}$ $109 / 1, \mathrm{P}=0.035)$, but not in stable asthmatics compared with controls. We found similar results in the analysis of atopic and non-atopic asthma.

Atopic and non-atopic asthmatics did not differ in $\mathrm{eCO}$ and total scores in asthma control test. We observed higher FeNO, total serum IgE, and blood eosinophils in atopic asthmatics in comparison with non-atopic and healthy asthmatic and control children. Interestingly, while comparing acute and stable asthmatics, atopic and non-atopic asthmatics between each other and with healthy subjects, we found only slightly decreased spirometric parameters in asthmatics, but comparing the children with isolated form of asthma with those who suffered from concomitant allergic rhinitis/rhinoconjunctivitis, several significant differences appeared. Isolated asthma was characterized by a significant reduction in FEV1 and FVC (compared to children with asthma+ARC) and with the decrease of FEF25-75\% and PEFR25-75\% (compared with both children with asthma+ARC and healthy controls). Regarding the atopy status, 63\% cases of isolated asthma and $71 \%$ of asthma associated with ARC were atopic (n.s.). Asthmatic children with concomitant ARC did not differ in any parameter compared with healthy children. Asthmatics without ARC showed the same values of $\mathrm{FeNO}$ and $\mathrm{eCO}$ as did healthy controls, but differed in total serum $\operatorname{IgE}$ and blood eosinophils. Both groups of asthmatic children showed no differences in eCO, asthma control test, total serum IgE levels, or blood eosinophils (absolute and percentage). Asthmatics with concomitant ARC had elevated of FeNO, eCO, total serum $\mathrm{IgE}$, and blood eosinophils compared with healthy controls and higher FeNO than isolated asthma (Table 1). Children with non-compliance to treatment had higher FeNO $(46.4 \pm 4.9$ vs. $18.1 \pm 1.3 \mathrm{ppb}, \mathrm{P}=0.001)$ and total serum $\operatorname{IgE}(371.0 \pm 73.0$ vs. $172.7 \pm 23.0 \mathrm{U} / \mathrm{ml}, \mathrm{P}=$ $0.010)$ compared with those who accepted our recommended therapy. Subjects with positive family history for allergic diseases (bronchial asthma, allergic rhinitis/rhinoconjunctivitis, atopic eczema) showed higher FeNO (27. $8 \pm 2.8$ vs. $20.1 \pm 1.8$ ppb, $\mathrm{P}=0.067)$ and blood eosinophils (absolute: $0.56 \pm 0.20 \times 10^{9}$ vs. 0.21 $\pm 0.02 \times 10^{9} / 1, \mathrm{P}<0.001$; percentage: $4.6 \pm 0.4$ vs. 3.0 $\pm 0.3 \%, \mathrm{P}=0.035)$. Regarding the gender, boys had higher FeNO than girls $(26.9 \pm 2.5$ vs. $20.6 \pm 2.0 \mathrm{ppb}$, $\mathrm{P}=0.048), \mathrm{eCO}(1.2 \pm 0.1$ vs. $0.7 \pm 0.1 \mathrm{ppm}, \mathrm{P}=$ $0.002)$, but did not differ in total serum $\operatorname{IgE}$ or eosinophil levels.

We also analyzed the possible correlation between the FeNO values and the results of other laboratory and clinical examinations. FeNO levels correlated significantly with the percentage of blood eosinophils 
(Fig. 1A), total serum IgE levels (Fig. 1B), \%predicted of forced vital capacity (Fig. 1C), and increasing age of the tested subjects (Fig. 1D). We found a marginally significant negative association between $\mathrm{FeNO}$ and the total score of asthma control test (not shown). FeNO was not related to eCO levels.

\section{DisCUSSION}

We analyzed differences in various indices measured in several subgroups of asthmatic children and healthy controls. We divided the children according to the differing characteristics: asthmatics vs. healthy control children, exacerbated vs. stable asthmatics, atopic vs. non-atopic children and those with isolated form of asthma vs. asthmatics with concomitant allergic rhinitis/rhinoconjunctivitis. The indices widely differed according to the clinical or laboratory characteristics of tested asthmatics. The levels of FeNO were increased in asthmatics in general, during acute exacerbation of the disease, in asthmatics with atopy and in children with asthma and other respiratory allergic co-morbidity. Interestingly, we were unable to detect significant differences in spirometric indices between asthmatics and healthy controls. It has been shown that the measurement of FeNO is more reliable in the diagnostic algorithm of $\mathrm{BA}$ than the results of lung function testing $[9,10]$. The application of FeNO as a diagnostic test for asthma could be limited by lower sensitivity. However, good specificity of FeNO could, in the presence of its low level, exclude the diagnosis of BA [11]. It has been suggested that elevated FeNO may help alert the clinician to the possibility of undiagnosed asthma [12]. Although none of the developed methods is optimal to predict an exacerbation of asthma, it has been confirmed that FeNO is helpful to this end, and it also could be used to guide therapy, adjust inhaled corticosteroids dose, or predict [13]. Smith et al [9] demonstrated that when comparing standard guidelines-directed care to the addition of FeNO, the latter group showed a significant reduction in the maintenance therapy required, while simultaneously achieving a trend toward a decrease in asthma exacerbations. The results of their study supported the hypothesis that control of airway inflammation can improve asthma control [9]. A combination of FeNO and FEV1 results could increase the sensitivity of $\mathrm{FeNO}$ in predicting the relapse of asthma [14]. It is confirmed by many authors that acute respiratory infections, which are usually the cause of asthma exacerbation, are connected with concomitant increases in FeNO. Interestingly, however, Kovesi et al [12] found that healthy children of general, unselected population without asthma, but with reported bronchitis or pneumonia in the past year had abnormally high FeNO concentrations without the presence of asthma. In the present study, asthmatics who did not comply with therapy had increased FeNO, which suggests that this parameter could also be used as an indicator of nonfollowing the therapeutic recommendations [15]. Similarly to our findings, children with asthma alone had lower FeNO than children with asthma and other allergies (eczema, rhinitis, and rhinoconjunctivitis) [12]. Welsh et al [16] found in a multivariate analysis that asthma, hay fever, and atopic dermatitis all significantly influenced FeNO in children. Thus, elevated FeNO could also result from atopic disease other than asthma [12]. Healthy children with positive allergy skin tests with or without serum eosinophilia may have elevated FeNO regardless of whether symptoms of asthma or allergic rhinitis are present [17]. Atopic asthma is associated with an elevation of FeNO in comparison with subjects suffering from non-atopic variant of this disease [18]. Recent study has revealed that both allergic and non-allergic asthma are related to increased FeNO levels, but only in never-smoking subjects. A limited value of FeNO to detect subjects with asthma among ex- and current smokers suggests the predominance of a non-eosinophilic inflammatory phenotype of asthma among never-smokers [19].

Isolated asthma did not differ in eCO from controls, but asthmatic children with allergic rhinitis showed elevation of eCO. Increased eCO in asthmatics may reflect the expression and activation of heme oxygenase- 1 in airways, due to inflammation and oxidative stress [20]. eCO concentration is increased during early and late phase of asthmatic reaction to allergen exposure, whereas FeNO is increased only in the late phase [21]. Although the differences in eCO are not as expressive as those in $\mathrm{FeNO}$, elevation of eCO correlates not only with airway inflammation, as does FeNO, but also with increased oxidative stress in asthmatic airways [2]. eCO could add information in the management of bronchial asthma, and also can help detect smokers among adolescent asthmatics, which, in turn, can help in critical evaluation of FeNO levels obtained in these patients.

Another aim of the present study was to analyze other potential factors that may influence FeNO. Elevated $\mathrm{FeNO}$ was associated with higher total serum IgE levels and eosinophilia, FVC, and increasing age. Boys had higher FeNO than girls. Other authors also found a significant contribution of gender $[5,6,12]$, age $[5,6,22]$, serum total $\operatorname{IgE}[17,22,23,24]$, or eosinophils $[17,22]$. In atopic asthmatics, serum $\mathrm{IgE}$ levels appear to reflect systemic (blood eosinophils) and organ-specific (FeNO) markers of allergic inflammation [22]. While we noted a weak but significant correlation between FeNO and some spirometric indices, other studies did not confirm that relationship [12]. Borderline association between the asthma control test score and FeNO suggests that these two parameters describe two different aspects of asthma clinical symptoms and inflammation in airways [25]. Since the correlation coefficients were in some cases low, although significant, it is probable that also other intrinsic and extrinsic factors significantly contribute to the FeNO variability, such as smoking, atopic status, concomitant upper or lower respiratory infection, testing during pollen season, allergen content in the air, presence of atopic eczema, etc. $[11,12,17]$.

We conclude that FeNO could not be expected to be the perfect inflammometer. However, FeNO presents an easy test which is helpful to target steroid treatment and to provide significant benefits in terms of less hyperresponsiveness and less inflammation. FeNO offers more for the day-to-day asthma management than any of the conventional lung function tests. 
The variability of FeNO results reported in the present study suggests the possible interplay of various bioactive factors in the formation and release of $\mathrm{NO}$, which should be taken into account in clinical decision-making based on the FeNO measurement.

Acknowledgements: Supported by Grant 2006/38-UK-05 from Ministry of Health and European Regional Development Fund. We would like to thank to Zina Domova, Jana Lettrichova, Martina Petrovicova and Iveta Plavnicka for technical help and assistance in the study.

Conflicts of interests: The authors reported no conflicts of interests in relation to this article.

\section{REFERENCES}

[1] Bacharier LB, Boner A, Carlsen K-H, Eigenmann PA, Frischer T, Gotz M, Helms PJ, Hunt J, Liu A, Papadopoulos N, Platts-Mills T, Pohunek P, Simons FE, Valvirta E, Wahn U, Wildhaber J; European Pediatric Asthma Group. Diagnosis and treatment of asthma in childhood: a PRACTAL consensus report. Allergy 2008; 63: 5-34.

[2] Babusikova E, Jesenak M, Durdik P, Dobrota D, Banovcin P. Exhaled carbon monoxide as a new marker of respiratory diseases in children. J Physiol Pharmacol 2008; 59 Suppl 6: 9-18.

[3] Cardinale F, de Benedictis FM, Muggeo V, Giordano P, Loffredo MS, Iacoviello G, Armenio L. Exhaled nitric oxide, total serum $\operatorname{IgE}$ and allergic sensitisation in childhood asthma and allergic rhinitis. Pediatr Allergy Immunol 2005; 16: 236-242.

[4] Dinakar C, Craff M, Laskowski D. Infants and toddlers without asthma with eczema have elevated exhaled nitric oxide levels. J Allergy Clin Immunol 2006; 117: 212-213.

[5] Van Asch CJ, Balemans WA, Rovers MM, Schilder AG, van der Ent CK. Atopic disease and exhaled nitric oxide in an unselected population of young adults. Ann Allergy Asthma Immunol 2008; 100: 59-65.

[6] Hervás D, Milán JM, Garde J. Differences in exhaled nitric oxide in atopic children. Allergol Immunopathol 2008; 36: 331-335.

[7] ATS/ERS recommendations for standardized procedures for the online and offline measurement of exhaled lower respiratory nitric oxide and nasal nitric oxide, 2005. Am J Respir Crit Care Med 2005; 171: 912-993.

[8] Miller MR, Hankinson J, Brusasco V, Burgos F, Casaburi R, Coates A, Crapo R, Enright P, van der Grinten CP, Gustafsson P, Jensen R, Johnson DC, MacIntyre N, McKay R, Navajas D, Pedersen OF, Pellegrino R, Viegi G, Wanger J; ATS/ERS Task Force. Standardisation of spirometry. Eur Respir J 2005; 26: 319-338.

[9] Smith AD, Cowan JO, Filsell S, McLachlan C, Monti-Sheehan G, Jackson P, Taylor DR. Diagnosing asthma: comparison between exhaled nitric oxide measurements and conventional tests. Am J Respir Crit Care Med 2004; 169: 473-478.

[10] Oppenheimer J, Sorkness CA. Does exhaled nitric oxide measurement have a role in asthma care? Ann Allergy Asthma Immunol 2009; 102: 253-255.

[11] Schneider A, Tilemann L, Schermer T, Gindner L, Laux G, Szecsenyi J, Meyer FJ. Diagnosing asthma in general practice with portable exhaled nitric oxide measurement results of a prospective diagnostic study. Respir Res 2009; 10: $10-15$

[12] Kovesi T, Dales R. Exhaled nitric oxide and respiratory symptoms in a community sample of school aged children. Pediatr Pulmonol 2008; 43: 1198-1205.
[13] Jones SL, Kittelston J, Cowan JO, Flannery EM, Hancox RJ, McLachlan CR, Taylor DR. The predictive value of exhaled nitric oxide measurements in assessing changes in asthma control. Am J Respir Crit Care Med 2001; 164: 738-743.

[14] Gelb AF, Flynn Taylor C, Shinar CM, Gutierrez C, Zamel $\mathrm{N}$. Role of spirometry and exhaled nitric oxide to predict exacerbations in treated asthmatics. Chest 2006; 129: 1492-1499.

[15] Pijnenburg MW, Bakker EM, Lever S, Hop WC, De Jongste JC. High fractional concentration of nitric oxide in exhaled air despite steroid treatment in asthmatic children. Clin Exp Allergy 2005; 35: 920-925.

[16] Welsh L, Lercher P, Horak E. Exhaled nitric oxide: interactions between asthma, hayfever, and atopic dermatitis. In school children. Pediatr Pulmonol 2007; 42: 693-698.

[17] Barreto M, Villa MP, Monti F, Bohmerova Z, Martella S, Montesano M, Darder MT, Ronchetti R. Additive effect of eosinophilia and atopy on exhaled nitric oxide levels in children with or without a history of respiratory symptoms. Pediatr Allergy Immunol 2005; 16: 52-58.

[18] Jouaville LF, Annesi-Maesano I, Nguyen LT, Bocage AS, Bedu M, Caillaud D. Interrelationships among asthma, atopy, rhinitis and exhaled nitric oxide in a populationbased sample of children. Clin Exp Allergy 2003; 33: 1506-1511.

[19] Malinovschi A, Janson C, Hogman M, Rolla G, Torén K, Norback D, Olin AC. Both allergic and nonallergic asth$\mathrm{ma}$ are associated with increased FENO levels, but only in never-smokers. Allergy 2009; 64: 55-61.

[20] Horvath I, Donnelly LE, Kiss A, Paredi P, Kharitonov SA, Barnes PJ. Raised levels of exhaled carbon monoxide are associated with an increased expression of heme oxygenase- 1 in airway macrophages in asthma: a new marker of oxidative stress. Thorax 1998; 53: 668-672

[21] Paredi P, Leckie MJ, Horvath I, Allegra L, Kharitonov SA, Barnes PJ. Changes in exhaled carbon monoxide and nitric oxide levels following allergen challenge in patients with asthma. Eur Respir J 1999; 13: 48-52.

[22] Sacco O, Sale R, Silvestri M, Serpero L, Sabatini F, Raynal ME, Biraghi M, Rossi GA. Total and allergen-specific IgE levels in serum reflect blood eosinophilia and fractional exhaled nitric oxide concentrations but not pulmonary functions in allergic asthmatic children sensitized to house dust mites. Pediatr Allergy Immunol 2003; 14 : 475-481.

[23] Lavesque MC, Hauswirth DW, Mervin-Blake S, Fernandez CA, Patch KB, Alexander KM, Allgood S, McNair PD, Allen AS, Sundy JS. Determinants of exhaled nitric oxide levels in healthy, non-smoking African American adults. J Allergy Clin Immunol 2008; 121: 396-402.

[24] Tepper RS, Llapur CJ, Jones MH, Tiller C, Coates C, Kimmel R, Kisling J, Katz B, Ding Y, Swigonski N. Expired nitric oxide and airway reactivity in infants at risk for asthma. J Allergy Clin Immunol 2008; 122: 760-765.

[25] Ko FW, Leung TF, Hui DS, Chu HY, Wong GW, Wong E, Tung AH, Lai CK. Asthma control test correlates well with the treatment decisions made by asthma specialists. Respirology 2009; 14: 559-566.

\section{Corresponding author:}

Milos Jesenak, M.D., Ph.D., MBA

Department of Pediatrics

Jessenius School of Medicine

Kollarova $2 \mathrm{St}$.

03659 Martin, Slovakia

Phone: +421903273531

Fax: +421043 4222678

Jesenak@gmail.com 